\title{
Sexual Boundaries and Subcultural Discipline ${ }^{\dagger^{*}}$
}

\author{
Patrick Keilty \\ 140 St. George Street, Toronto, Ontario, Canada M5S 3G6, \\ <pkeilty@gmail.com>
}

\begin{abstract}
Patrick Keilty is an Assistant Professor in the Faculty of Information at the University of Toronto. His writing examines and critiques knowledge structures, digital culture, digital humanities, gender and sexuality, intersectionality, and science and technology studies. With Rebecca Hong, he is co-editor of Feminist and Queer Information Studies Reader (forthcoming). With Katie Shilton, he is currently coediting Critical Information Studies. In addition, he is editing Gender and Sexual Boundaries and preparing a monograph entitled Seeking Sex: Embodiment and Electronic Culture, which examines how the Internet has reconstituted our ways of being sexual. His most recent essays have appeared in Knowledge Organization, Proceedings of the iConference, and InterActions. He has recently presented papers at the iConference, the Society for Cinema and Media Studies, and Thinking Gender.
\end{abstract}

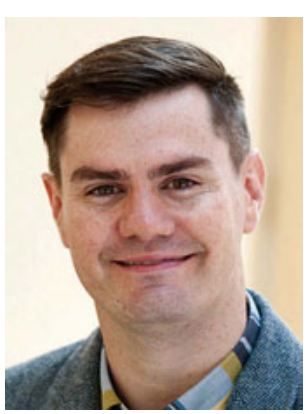

Keilty, Patrick. Sexual Boundaries and Subcultural Discipline. Knowledge Organization. 39(6), 417431. 57 references.

\begin{abstract}
The purpose of this essay is to demonstrate that the mechanisms of power around classifications of gender and sexuality are not always top-down or bottom-up. Instead, the weight of social discipline among members of sexual subcultures themselves helps to create these classifications, often reflecting the nomenclature of subjects and desires within sexual subcultures in a complex relationship to a dominant culture. Critically examining two benchmarks in the development of sexual nomenclature within queer subcultures, this paper finds its evidence in George Chauncey's little known analysis (1985) of a navy investigation of male homosexuality at the Newport Naval Training Station during the World War I era and in contemporary folksonomic classifications of representations of queer desire within Xtube, a database of online pornography. Social discipline within these sexual subcultures occurs in the stabilization of nomenclature through socialization and through members' overt intervention into each others' self-understanding. Both the Newport and Xtube evidence also reveals a complex social and cultural structure among members of sexual subcultures by drawing our attention to the particularity of various modes of sexual being and the relationship between those modes and particular configurations of sexual identity. In the process, this paper allows us to reassess, first, a presupposition of folksonomies as free of discipline allowing for their emancipatory potential and, second, the prevailing binary understandings of authority in the development of sexual nomenclatures and classifications as either top-down or bottom-up.
\end{abstract}

Received 9 May 2012; Revised 3 July 2012; Accepted 3 July 2012

$\dagger$ The author is extravagantly indebted to Melissa Adler for allowing him to lend, borrow, and exchange ideas with her. He owes the inspiration for this paper to conversations with George Chauncey and Jim Schultz. Special thanks go to Dustin Friedman and Matthew Schuman for their assistance. As ever, Johanna Drucker, Jonathan Furner, and Greg Leazer provided encouragement.

*This article is an expansion of the author's conference paper, which appeared in Knowledge Organization 39.5-Ed.

\subsection{Introduction}

The purpose of this essay is to demonstrate that the mechanisms of power around classifications of gender and sexuality are not always top-down or bottomup. Instead, the weight of social discipline among members of sexual subcultures themselves helps to create these classifications, often reflecting the nomenclature of subjects and desires within sexual subcultures in a complex relationship to a dominant culture. The past half-century has seen an established body of scholarship that documents and forcefully 
critiques institutionally sanctioned and authoritative forms of classification that order human interaction. Some prominent examples include, among others, Geoffrey Bowker and Susan Leigh Star's Sorting Things Out: Classification and Its Consequences (1999), George Lakoff's Women, Fire, and Dangerous Things: What Categories Reveal about the Mind (1997), V. Y. Mudimbe's The Invention of Africa: Gnosis, Philosophy, and the Order of Knowledge (1988), and, of course, Michel Foucault's The Order of Things: An Archeology of the Human Sciences (trans. 1970). These works reveal the ways in which the classificatory structures and knowledge organization of government and medical institutions have both productive and coercive effects. Each of these texts encourages readers to think critically about the process at the moral and political core of institutionally sanctioned and authoritative classificatory work.

The same period has seen an established body of work concerning the influence of authoritative classifications of gender and sexual subcultures. Foucault's History of Sexuality, Volume 1: The Will to Knowledge (trans. 1978) is perhaps the most influential of such scholarship. In examining the creation of sexual subjects during the late nineteenth century, Foucault argues that the proliferation of medical and legal discourse around sexuality paradoxically causes us to internalize categories of identity, thereby forcing us to collude in our own disciplining. Following Foucault, a number of scholars have examined the "invention of the homosexual," that is, the determination, around 1900 , that homosexuality was limited to certain identifiable individuals for whom it was an involuntary sexual orientation of some biological or psychological origin. Like Foucault, the most prominent advocates of this thesis have argued that the medical and legal discourse on homosexuality that emerged in the late nineteenth century played a determining role in this process, by creating and popularizing the medicolegal model of homosexual behavior. It was on the basis of this new model that individuals came to assume a homosexual identity (and to be labeled as such in popular culture), as sexual perverts different in nature from others, rather than as sinners whose sinful nature is the lot of humanity. Foucault's History of Sexuality has had such an outsize influence on our prevailing understandings of the creation of sexual subjects and identities that it would be impossible to enumerate the various reiterations of his thesis among gender and sexual scholars over the past halfcentury. ${ }^{1}$ It is sufficient enough to identity only a few, among many, of the early influential works that rely on his thesis, including Jeffrey Weeks (1977), Lillian Faderman (1981), D. A. Miller (1989), Nancy Armstrong (1990), Eve Sedgwick (1990), Jonathan Dollimore (1991), David Halperin (1997), and Joseph Bristow (1997).

With particular proliferation in the last decade, library and information scholarship, too, critiques the effects of institutionally sanctioned and authoritative gender and sexual subject categories, including Sanford Berman (1981 and 1990), Ellen Greenblatt (1990 and 2011), Hope Olson (1998, 2001, 2002, and 2007), Grant Campbell (2001 and 2004), Andrew Lau (2008), Ben Christiansen (2008 and 2011), Patrick Keilty (2009), J. K. Rawson (2009), Matt Johnson (2010), Melissa Adler (2009, 2012, and 2013 forthcoming), and Analisa Ornelas (2011), to name only a few. Most of these scholars have forcefully shown the way the Library of Congress Subject Headings or the Dewey Decimal Classification System do not reflect the nomenclatures accustomed to gender and sexual non-conforming people. Such a disconnect, they argue, not only restricts queer people's access to information, but also forces these subjects to navigate and adopt offensive nomenclature about their very person. These scholars often cast the "power to name," to borrow Olson's famous phrase, as a matter of absolute authority imposed on a sexual subculture, in which the mechanisms of power around classifications of gender and sexuality occur in a top-down fashion. It seems reasonable, then, that scholars committed to counteracting such hegemony might look to bottom-up mechanisms of power for naming gender and sexual subject positions that do not adhere to a particular institution's or dominant culture's roles and nomenclature.

In the past few years, Lau, Adler, and Ornelas have suggested that folksonomic forms of classification, e.g., tagging, are one way to augment institutionally sanctioned forms of classification. Lau, Adler, and Ornelas view folksonomies as having potential emancipatory power. For Lau, "standardized classification alludes to the authority of a privileged ontology and/ or perspective, and runs the risk of perpetuating information imperialism' through homogenization.” In order to counteract such imperialism, Lau finds that "folksonomies acknowledge local and situated knowledges by including the voices of multiple ontologies, rather than prescribing how information should be organized" (2008, 1). Adler persuasively demonstrates the emancipatory capacity of folksonomies for accessing transgender books in LibraryThing. She describes it as a democratizing force that responds quickly to 
shifts and expansions of categories, even if it lacks control $(2009,309)$. "Perhaps the greatest strength of folksonomies," writes Adler, "is that they allow everyone who is interested in the subject to add to the vocabulary, reflecting all users' positions without bias and without definitive rules" $(2009,316)$.

What these pioneering scholars miss, however, is that folksonomies are not free of disciplinary forces; they are not entirely free of control. The mechanisms of power around the development of folksonomies, specifically the nomenclature of non-normative sexual subcultures, do not operate strictly in a top-down or bottom-up fashion. Instead, as I show later in this essay, the mechanisms of power occur horizontally as well as vertically.

This is not to say that folksonomies have no emancipatory potential. Nor is it to say that the mechanisms of power around folksonomies operate the same way as institutionally sanctioned forms of classification. Instead, I will describe a complex understanding of the 'power to name' as it occurs within a sexual subculture, always in relation to a dominant culture. Folksonomies certainly do have the power to counteract hegemonic forms of classification by displacing the absolute authority of an institution. Yet it is not the case that hegemony is absent from folksonomies. Control within a sexual subculture reveals the socially dynamic ways in which nomenclature develops among individuals, always in relation to each other and a dominant culture. It is never the case that individuals act in isolation or in a vacuum in the process of naming. However productive folksonomies are for counteracting "information imperialism," and however productive they are for retrieving information, they are also highly regulatory. We are not, as I will show, entirely free to choose our subject positions in the process of naming. This is because the "exploration" of subject positions within folksonomies is always constrained by a logic requiring instantly recognizable cues, regularized under the conventions of a particular sexual subculture that one inhabits. The sociability of a particular subculture, in fact, relies on such regulatory strictures, just as effective information retrieval relies on control.

The socially dynamic way in which folksonomies develop is not lost on Adler or Lau, though neither of them examines it, or its mechanism of power, in much detail. ${ }^{2}$ Instead, they acknowledge these dynamics in passing. Adler writes, "Members of communities will frequently adopt common vocabularies." She quickly adds, "In fact, within a folksonomy, a common language begins to emerge as users share tags" $(2009,316)$. Adler cites a study that finds that tagging patterns stabilize as the number of users increase (Golder and Huberman 2006). ${ }^{3}$ Meanwhile, Lau repeatedly acknowledges that individuals within a community generate tags collectively. He underscores the "social aspect of folksonomies as products of negotiation" $(2008,7)$, and further claims, "folksonomies are predicated on the activity of the community, their successes in linkage and connectivity are contingent on the sharing of metadata" $(2008,8)$. This collective engagement in the development of folksonomies-of sharing, negotiating, and stabilizingspeaks to the very definition of folksonomy, a portmanteau of folk and taxonomy, meant to describe the communal nature of creating systemic classification. Thus, Adler and Lau acknowledge what some critics of folksonomies miss-that folksonomies are not always willy-nilly, particularistic, and idiosyncratic, somehow occurring outside of social relations and outside a language common to a particular community. ${ }^{4}$ By definition, folksonomies are not so relativistic as to be useless. Although nomenclature can certainly develop idiosyncratically, it is also, and in most cases, experienced both generally and conventionally-in the first instance, according to general characteristics of language, such as semiotics, grammar, syntax, meter, and rhythm, and, in the second instance, according to usually transparent and dominant cultural (or subcultural) habits that are not so much determining as they are regulative.

\subsection{Forget Foucault?}

In order to reassess the prevailing understanding of the mechanisms of power around classifications of gender and sexuality, we need to examine its theoretical underpinnings. A significant amount of the literature concerning classifications of gender and sexuality within information studies cites Foucault as a major thinker guiding their analyses. Those particularly reliant on Foucault include Campbell (2001), Lau (2008), Keilty (2009), and Adler (2009 and forthcoming). Each of these scholars relies on Foucault's understanding of the relationship between power, knowledge, and language in relation to institutions, as variously described in History of Sexuality, Volume I (trans. 1978), Order of Things (trans. 1977), and The Archeology of Knowledge (trans. 1972). Space limitations allow me only to highlight the specific argument within Foucault's oeuvre that relates to the topic of this essay, and as a result, I have to omit some of his most fruitful thinking for understanding 
power, knowledge, and institutions more broadly. It is only in History of Sexuality that Foucault specifically discusses the development of sexual subjects and identities, so it will be the focus of my analysis below.

Such reliance on Foucault is certainly understandable given his outsize influence on discussions concerning the development of sexual subjects and identities in relation to institutional authority. It is also understandable when we recall that the Library of Congress relies on medical literature, precisely what Foucault sought to critique, when it adopts the term homosexuality in 1946 as an authorized subject heading. Adler claims, "The Library of Congress is precisely the kind of institution to which Foucault refers" $(2009,311)$. The concept of homosexuality had previously been subsumed under the heading Sexual perversion, and "a 'see also from' reference to Sexual perversion continued to appear as late as 1972," as Greenblatt succinctly describes $(2011,214)$. To my mind, there has been, as yet, no detailed understanding of why the Library of Congress adopts that word at that time (this is an area for future research.) Greenblatt (2011) surmises that it had won out over other terms within medical literature because of its flexibility. "Based on Greek and Latin roots," she writes, "it had an international appeal due to its adaptability in different languages and its potential for deriving opposable terminology, i.e. such terms as heterosexual and bisexnal" (2011, 214). Heike Bauer (2009) also explains that fin-de-siècle sexologists-such as Karl Henrich Ulrichs, Richard Von Krafft-Ebing, and Magnus Hirschfeld-relied on the classical humanist tradition as a rhetorical tool to argue that same-sex desire was spiritual and philosophical. At the time, the well educated of Western Europe had considerable training in Greek and Latin, and privileged classical humanism as the foundation of Western society. ${ }^{5}$

While we may not have a detailed history of the Library of Congress's adoption of the term "homosexuality," we may be able to deduce some understanding (though certainly not conclusive) from what we know about studies into "homosexuality" that had occurred leading up to 1946. We know three things that might have had an influence on the Library of Congress's decision. First, we know, as Greenblatt indicates, that the term "homosexuality" had circulated widely within psychiatric literature on the topic. The word had first appeared in a letter from Károly Mária Kertbeny to Karl Henrich Ulrichs, the famous German sexologist, in $1868 .{ }^{6}$ It had appeared in medical journals in the United States by the 1890s and had appeared, however limited, in mainstream publica- tions by the 1920s (Greenblatt 2011, 214). We also know that the term "homosexuality" appears in U.S. government publications during World War II, when psychiatrists begin to occupy an influential position in the U.S. military, which, according to Chauncey, "used them to help select and manage the more than 15 million men and women it mobilized for the war" $(1985,210) .^{7}$ As a result of investigations into sexual perversion among military men and women during wartime, a proliferation of studies into homosexuality began to appear in the medical literature, and, by 1948, Alfred Kinsey had published the first of his remarkably popular reports on human sexuality. In an attempt to manage the proliferation of such medical literature, the Library of Congress presumably adopted the predominant nomenclature within the literature at that time. What's more, by 1946, as a result of psychiatric influence in the U.S. military, the term had already had a controlling influence within U.S. government publications and among U.S. government officials, who would continue to use the category to identify people they wished to root out of the military and government agencies from WWII until President Clinton's Executive Order (\#11478) in 1998 and the repeal of "Don't Ask, Don't Tell" in 2011. ${ }^{8}$ Finally, as I will explain in further detail in the following section, we know that a shift in popular understandings of same-sex sexual perversion took place beginning in the late 1940s - from something ambiguously predicated on gender non-conformity to something consolidated around particular practices and desires. It is, therefore, reasonable to assume that that the Library of Congress's decision to adopt the term "homosexuality" in 1946 at least partly reflects the term's wide usage within government and medical literature at that time.

All of this seemingly fortifies Foucault's thesis that the proliferation of medical (and legal) discourse around sexuality paradoxically causes us to internalize categories of identity, thereby forcing us to collude in our own disciplining. After all, I have just demonstrated how medical discourse consolidates an identity category that circulates widely within a variety of institutions, such as psychiatry, the U.S. military, the law, and the Library of Congress. These institutions thereby label particular subjects, who then, in turn, presumably rely on such nomenclature to negotiate these institutions. In examining the Library of Congress, Adler $(2009,311)$ explains the process this way: "As a category becomes institutionalized, it affects the members of the category, and meaning is negotiated among the interested parties within a dominant 
framework." In doing so, according to Foucault's thesis, subjects participate in consolidating the very identity category that institutions use to regulate them. "Categories have the power to shape perceptions of the self," writes Adler (2009, 311-312), "and they tend to play an active part in a wider discourse that shapes others' views of the people to which the categories are intended to refer." For Adler, following Foucault, medical discourse on homosexuality played a determinative role in the process of creating, consolidating, sustaining, and popularizing the term "homosexuality" as an identity for sexual deviants, distinguishable from other people.

Since Foucault, however, prominent historians have refined our analysis of the relationship between homosexual behavior and identity. Perhaps first among such historians, George Chauncey found that medical discourse played little or no role in the shaping of poor and working-class homosexual identities and categories for many years after the discourse had begun. Chauncey $(1985,203)$ argues that there is "no logical reason to expect that discussions carried on in elite journals whose distribution was limited to members of the medical and legal professions would have any immediate effect on the larger culture, particularly the working-class". Furthermore, if we were to accept Foucault's thesis, such identity formation would have taken hold half a century before the Library of Congress adopted the term "homosexuality" as an authorized subject heading in 1946.

Adler's overarching point - that categories have the power to shape perceptions of the self and others' perception of oneself-does not necessarily rely on Foucault. Adler also cites Judith Butler's (2004) theory on language and intelligibility to argue, "the act of naming authenticates an entity's existence" (Adler 2009, 312). ${ }^{9}$ Butler's argument is different from Foucault's in an important way. Both philosophers would agree with Adler that words affect our perceptions of meaning and reality. However, the power to name, in Butler's rendering, does not find absolute authority in institutions that, then, determine individual identities. Instead, Butler $(2004,1)$ points to her earlier work on the performative nature of gender to define it as a "practice of improvisation within a scene of constraint." In other words, gender is performed socially and constrained by social convention. That gender is a social construction-an axiom among feminist and queer scholars-is to say, in part, that our understandings of gender arise from our social relations. Thus, Butler acknowledges the socially dynamic way in which our conceptual boundaries of gender develop, revealing horizontal power as well as vertical power. In this way, for Butler, ideology produces identity-not the other way around, as Foucault would have it. Ideology is simply a set of dominant conventions within a particular culture or subculture; it is the act of socialization, or the process of 'received consciousness' that arises out of social relations.

To be fair, Adler does not map Foucault's thesis directly on to the Library of Congress. As with other information scholars I cite, Adler relies on Foucault in indirect or nuanced ways that gesture towards his idea for the potential for institutions to discipline. In this way, Foucault has been cited de rigueur, in order to pay tribute to his outsize influence on this topic, however much subsequent historians have refined his original thesis. If we did attempt to map Foucault's determining thesis onto the classificatory strictures of the Library of Congress, it would significantly contravene our guiding complaint about the ineffectual nature of the Library of Congress Subject Headings (LCSH) for accessing information about nonnormative gender and sexuality. While no scholar within information studies attempts such a direct mapping, it is instructive to understand the limits of Foucault's thesis as it regards information organization, given that a number of recent studies cite him as a guiding influence.

I have already shown some of these limitations. In addition, we cannot claim, on the one hand, that $L C S H$ caused us to internalize categories of identities-thereby forcing us to collude in our own disciplining-while, on the other hand, claim that $L C S H$ does not reflect the nomenclature used by sexual subcultures to describe themselves. If LCSH indeed played a determining role in our identity formations and subject positions, then we would have been disciplined to adopt and accept the conceptual categories of ourselves that $L C S H$ provides. The fact that we feel $L C S H$ does not reflect the myriad of subject positions within a particular sexual subculture reveals the limits of its disciplinary power. It isn't that the Library of Congress has no disciplinary power; we must just be careful about how far we claim its disciplinary power extends. Instead, institutional disciplinary power occurs always in relation to another, horizontal kind of power: the weight of social discipline among members of sexual subcultures themselves.

\subsection{Horizontal discipline}

In his now infamous class at the University of Michigan, entitled "How to Be Gay: Male Homosexuality 
and Initiation," David Halperin encourages students to think critically about the odd notion that there are right ways and wrong ways to be gay, that homosexuality is not just a set of practices or desires, but an identification with and participation in shared cultural forms. Learning these cultural forms-such as specific tastes in music and movies, camp, diva-worship, drag, muscle-worship, or political activism-is something one learns, Halperin contends, from fellow members of a particular subculture. Halperin acknowledges, of course, that queer subcultures are not monolithic, and that they are culturally, geographically, and historically contingent. His course ignited the furor of the American Family Association and other right-wing groups, who urged the thenGovernor, Jennifer Granholm, the state legislature, and the University of Michigan's Board of Regents to defund his "radical homosexual agenda." 10 They had accused Halperin of teaching students how to become homosexual. No doubt, Halperin deliberately intended for the title of his course to provoke the suspicions of social conservatives, who have long accused homosexuals of 'initiating' people into a cult.

In his examination of 'initiation,' Halperin reveals the disciplinary power within subcultures, the members of which regulate each other according to recognizable cues and mores that, through repetition, become a particular community's conventions and habits, or, as Butler has it, ideology. I have previously referred to this process as socialization or 'received consciousness.' For Halperin, the process of initiation serves to regularize and perpetuate communally held and agreed upon cultural forms. For Chauncey, a similar regulatory process takes place in the development of nomenclatures within sexual subcultures. Chauncey takes as his case study an investigation by the U.S. Navy into male sexual deviance at the Newport Naval Training Station in 1919-1920. Chauncey reconstructs the social organization and selfunderstanding of homosexually active sailors to reveal that the construction of sexual boundaries and nomenclature at that time, which is different from our own, occurred when members of the subculture regulated each other, always in relation to a dominant culture. In the process, he shows what little influence medico-legal discourse had on the social organization and self-understanding of members within this subculture, more than thirty years after the discourse of homosexuality had begun.

On the basis of 3,500 pages of testimony produced by the investigation, Chauncey reconstructs the organization of a queer subculture between 1919-1920, how participants viewed their behavior, and how the larger community viewed them, thus providing a benchmark for generalizations about the historical development of queer identities and communities. The testimony reveals a highly developed and varied queer subculture, with a strong sense of collective identity on the part of many of its participants, who sustained a complex system of personal identities that structured their relationships. Different from today, many of the elaborate sexual categories within the subculture depended on the preponderance of one's personality traits, as adhering to the gender roles ascribed to men or women. So while witnesses agreed that two men engaged in same-sex sexual relations, they disagreed about whether both men or only the man playing the 'woman's part' should be labeled as 'queer.'

Chauncey $(1985,193)$ writes, "the determining criteria in labeling a man as 'straight' (their term) or 'queer' was not the extent of his homosexual activity, but the gender role he assumed. The only men who sharply differentiated themselves from other men, labeling themselves 'queer,' were those who assumed the sexual and other cultural roles ascribed to women.” In early twentieth-century medical literature, men who assumed the sexual and cultural roles ascribed to women might have been termed 'inverts' because they not only expressed homosexual desire but 'inverted' (or reversed) their gender role (Chauncey 1983). While words like 'invert,' and 'homosexuality' were common within the medical literature at the time, neither the investigators nor the members of the queer subculture relied on those words. In the only instance in which a member of the group used the word 'invert,' the man indicated that he had heard the word in theatre circles, not through reading any literature. Thus, members of the subculture grouped themselves as 'queers' on the basis of their effeminate personality traits and their sexual role as receptive (rather than insertive). Today, labels such as 'top' and 'bottom'-which connote insertive and receptive sexual roles, respectively-do not necessarily align along the lines of effeminacy and masculinity in, say, a leather bar in Hollywood, where 'butch bottom' is a common category.

The sexual categories of Newport's queer subculture were far more elaborate than simply 'straights' and 'queers.' A variety of other terms further distinguished members of the subculture on the basis of sexual practices they preferred-so that 'queers' belonged to one of three subsets: 'fairies, ${ }^{11}$ who prefer to perform fellatio, 'pogues,' who like to be 'browned' (or anally penetrated), and 'two-way artists,' who en- 
joy both. An elaborate nomenclature also existed for men who conformed to masculine gender norms. None of these men behaved effeminately or took the 'women's part' in sexual relations. These men were described as 'husbands' to the 'ladies.' According to Chauncey $(1985,192)$, "Some husbands entered into steady, loving relationships with individual men known as queer; witnesses spoke of couples who took trips together and maintained monogamous relationships." 'Queers' within the sexual subculture further divided the 'straight' population into two groups: those who would reject their sexual advances and those who would accept them. 'Trade' became the label for those men who would accept their advances; although, even among 'trade,' queers realized that some men would participate more actively than others in sexual encounters, making the category somewhat ambiguous. The broader 'straight' category becomes even more ambiguous when we learn of the difficulty the dominant culture had in deciding whether 'straight' men who accepted the sexual advances of 'queers' should be considered sexually perverse. Of the 'straight' category Chauncey $(1985,192)$ writes:

But the ambiguity of the sexual category such men occupied was reflected in the difficulty observers found in labeling them. The navy, which sometimes grouped such men with the queers as 'perverts,' found it could only satisfactorily identify them by describing what they did, rather than naming what they were .... Even the queers' terms for such men-'friends' and 'husbands'-identified them only in relation to the queers, rather than according them an autonomous sexual identity.

The reason it was difficult to assign an autonomous sexual identity to men who conformed to masculine gender roles-e.g., 'husbands' and 'friends'-is because the prevailing definition of sexual perversion at that time relied on one's gender-nonconforming status. It would not be until the middle part of the twentieth century that understandings of sexual perversion would shift from gender nonconformity to an emphasis on particular sexual practices and desires. This shift largely owes to extravagantly popular studies of human sexuality that attempted to quantify same-sex sexual behavior, without much concern for gender conforming and nonconforming characteristics, most notably Alfred Kinsey's studies. ${ }^{12}$ Indeed, a major impact of Kinsey's 1948 study is his finding that an astonishing number of men self-reported hav- ing had same-sex sexual relations, and an even larger number reported repeatedly having had same-sex sexual desires, which challenged then-conventional beliefs about sexuality generally and homosexuality in particular. No longer seen as an isolated occurrence, homosexuality came to be seen as a widespread and reoccurring phenomenon within society, one that included many men, regardless of their gender conformity. By the middle part of the century, genderconforming men who engaged in same-sex practices or desires were not simply sinners whose sinful nature was the lot of humanity, but were different in nature from other people and could be ascribed an autonomous sexual identity. ${ }^{13}$

The categories of the queer subculture that Chauncey describes reveal that their social organization and self-understanding are deeply embedded in that of the larger culture. As Chauncey $(1985,193)$ shows, its members "reproduced many of the social forms of gendered heterosexuality, with some men playing 'the women's part' in relationships with conventionally masculine 'husbands". The existence of the sexual subculture also provided a means for these men to structure vague feelings of sexual and gender difference into distinctive personal identities. Sexual subcultures, writes Chauncey $(1985,193)$,

facilitated people's exploration and organization of their homosexuality by offering them support in the face of social opprobrium and providing them with guidelines for how to organize their feelings of difference into a particular social form of homosexuality, a coherent identity and a way of life. The [subculture] offered men a means to assume social roles which they perceived to be more congruent with their inner natures than those prescribed to them by the dominant culture, and sometimes gave them remarkable strength to publically defy social convention.

Indeed, the social organization of queer subcultures always occurs in relation to the dominant culture. The very existence and structure of the group reflects an attempt to survive into a culture of social disapproval. It is an attempt at exploration within and against those norms. Part of this survival means reconstituting the dominant social organization for their own purposes, as we have seen in the way the queer subculture in Newport takes up the dominant nomenclature-e.g. 'husband,' 'ladies,' and 'women's part.' 
Yet the freedom of exploration within this culture is not only constrained and influenced by a dominant culture. Members of the subculture themselves also heavily regulated each other's exploration. The weight of a dominant culture's disapproval led people within the subculture to insist on a form of solidarity that required conformity to its own standards. "To be accepted by the [subculture]," writes Chauncey $(1985,193)$, "one had to assume the role of pogue, fairy, two-way artist, or husband, and to present oneself publically in a manner consistent with that labeling." Chauncey reveals that the behaviors of members of the subculture who tried to explore outside the boundaries of their category were seen as inappropriate, as in the case when a 'fairy' tried to 'brown' another member of the subculture, which was incongruent with the fairy's role as a 'queer.'

Members of the subculture not only disapproved of non-conforming exploration, some of them also believed they could identify men as pogues or fairies even if the men had not recognized themselves as such. Chauncey $(1985,193)$ shows that these men sometimes intervened to accelerate the process of self-discovery.

The [subculture] scrutinized newly arrived recruits at the YMCA for likely sexual partners and 'queers,' and at least one case is recorded of their approaching an effeminate but 'straight'identified man named Rogers in order to bring him out as a pogue. While he recalled always having been somewhat effeminate, after he joined the [subculture], Rogers began using makeup 'because the others did,' assumed the name 'Kitty Gordon,' and developed a steady relationship with another man (his 'husband').

Such were the regulatory strictures among members of the subculture themselves. They felt that not only could they intervene into the destinies of their fellow members, but also that they could precisely identity people's 'true natures.' Hence, social organization, self-understanding, and categories of identity developed under the weight of social discipline between members within the subculture, always in relation to a dominant culture.

\subsection{Tagging}

Chauncey's study of the social organization and nomenclature of a queer subculture from 1919-1920 resonates in some ways with the development of no- menclatures within contemporary online queer subcultures. There are, of course, significant differences. Three major differences come immediately to mind. First, the social organization of same-sex sexual subcultures in the early twentieth century bears little resemblance to same-sex sexual subcultures today. Sexual roles have been reorganized: insertive does not necessarily pair with receptive, just as masculine does not necessarily pair with feminine. The word 'queer' no longer refers strictly to effeminate men but often encompasses a wide rage of non-normative gender and sexual subject positions. (However, in recent years, even that is changing, as 'queer' becomes an evershifting category, whose dimensions can't be subsumed under gender and sexuality alone: it has been applied to race, ethnicity, post-colonial nationality, and transnationalism, among other identity-constituting, identity-fracturing discourses.) 'Husband' no longer means a masculine man who forms a committed relationship to an effeminate man. Today, while the term popularly retains notions of long-term commitments (usually within the institution of marriage), it does not necessarily have a gender-conforming connotation. 'Pogue' and 'two-way artist' have completely gone out of circulation and would be unrecognizable to members of a contemporary gay subculture. 'Straight' has become a much more consolidated identity category, referring to one's sexual preference for the opposite sex, rather than referring to masculine men generally. 'Trade' no longer refers to masculine men who will accept the advances of effeminate men. It now almost always accompanies the word 'rough'which proceeds it—and can refer to a man with whom one engages in public sex-such as a park, alleyway, or restroom-considered 'rough' because the practice runs the risk of legal sanction. It can also retain a class distinction, referring to working-class men whose physical appearance is presumably less 'clean-cut' than that of professional men.

Second, the relationship between many nonnormative gender and sexual subcultures and the dominant culture has significantly altered since the early twentieth century. Since that time, we have seen an unprecedented cultural richness, assertiveness, and cohesion for people with non-normative gender and sexuality, as well as a gradual acceptance by the larger culture of people identifying as gay, lesbian, bisexual, and transgender (LGBT). LGBT political mobilization-sometimes together, sometimes separatelyhas enacted unprecedented change within the dominant society, so much so that some scholars have critiqued the ways in which otherwise non-normative 
gender and sexual subjects have been enfolded into the nation-state and realigned for the purpose of national interests, sometimes called "homonationalism" or, in specific instances, "pinkwashing." "14

Third, online sociability is different in significant ways than face-to-face encounters. Much has been made lately about some of these differences, particularly for members of queer subcultures. The gay bar and club, for example, are no longer the primary ways in which to encounter people who share your gender or sexual differences. Now that individuals can cruise for sex and relationships online, in the comfort and privacy of their homes, there is no need to socialize with a variety of people in face-to-face encounters. While we still encounter a variety of people online, so goes the thinking, face-to-face relations have been diminished. On the other hand, individuals who are socially inhibited in a face-to-face encounter may find that an online encounter removes many of the situational factors that spark anxiety. In an online context, individuals also have more opportunity for anonymity and for creating different profiles and different identities, which potentially allows for greater role-playing and greater deception.

Two aspects of Chauncey's analysis resonate with the development of queer subcultural nomenclature on Xtube, an online pornographic video hosting service. First, tagging within Xtube reveals highly developed and varied queer social organization and nomenclature; and second, the tags develop under the weight of social discipline among members of the subculture themselves, always in relation to a dominant culture. Tagging practices within Xtube (and similar sites) serve as a benchmark in studying the development of sexual nomenclatures because they reveal how members of the subculture view themselves, how they view others, and how members of the larger community view them. With more than nine million 'members,' Xtube claims to be "the first adult website to allow members to upload their own homemade photos and videos" (n.d.). ${ }^{15}$ It is effectively YouTube for pornography, but with far more social networking design elements, including live camera exhibitionism between members, a dating portal, a wiki, blogs, groups, forums, quizzes, and polls, to name a few. It also allows members to view each other's profiles, to follow a particular member's images and videos, and to follow which images and videos a particular member likes. Because pornography is representational, it enables us to study societal gender and sexuality. Pornography is, according to Laura Kipnis $(1999,161)$, "intensely and relentlessly about us. It involves the roots of our cul- ture and the deepest corners of the self." As such, the tagging that surrounds pornography enables us to study societal gender and sexual nomenclature and social organization.

As I show in a previous essay (Keilty 2009), Xtube attempts to provide a near instantaneous mass mediation and dissemination of sexual representation. One might argue that this wealth of images offers an emancipatory scenario whereby subjects can project their virtual selves into a seemingly endless variety of environments, and to embody an infinite number of freely chosen subject positions, roles, and desires. In doing so, we may think Xtube allows for an exploration of the self and one's identity in relation to others (indeed, reliant on others as viewers), or, in other words, an exploration of various stylistics of the self. ${ }^{16}$ Yet, in my analysis of the eroticization of hierarchical knowledge structures, I find (Keilty 2009, 246):

Xtube's classification functions to guide, if not overtly discipline, subjects-both the subjects of the images and the viewer as subject. It is evidence of an environment in which desires and subject positions are produced as essential standards through a discourse of hierarchical categorization and classification. Images on Xtube are available to the viewer only through the negotiation of a coarse and elaborate typology in which subject positions are fixed and defined in relation to each other.

Some of these "categories" (Xtube's own language) are authoritative or prescriptive, developed by Xtube's administrators. Xtube requires viewers to select between one and three categories from among more than 30 prescriptive categories to describe an image or video when uploading it to the website. Some of these prescriptive categories include Amateur, Anal, Asian, BDSM, Bisexual, Bush, Ebony, Fetish, Fursuits, Groupsex, Hardcore, Interracial, Jerkoff, Latina, Lesbian, Mature, MILF, News, Softcore, Swingers, Teens, Toys, and Voyeur. Xtube also requires that members choose whether the video is gay or straight, and whether the subject of the video is Single Man, Single Woman, Man and Man, Men and Women, Women and Women, or Transexuals. These are members' only choices, and they probably say more about Xtube's administrators than they do about a dominant culture. ${ }^{17}$ Members can also add a title, description, and tags, which Xtube does not predetermine. As a result of these various categorical configurations, members can perform faceted searches that mix and match any 
of the various categories and tags. Members can search multiple categories and tags or a single category or tag simultaneously, all of which has been hyperlinked. Keyword searches include titles and descriptions, which have not been hyperlinked.

A member's "exploration" within Xtube is always already constrained by a logic of recognizable cues that are regularized, disciplined, and stabilized according to received forms of sex and desire. Tagging occurs in relation to Xtube's prescriptive categories. As such, members' gender and sexual organization is always named, regulated, and stabilized in advance, along a coarse axis of registers. Because the identity of one's gender and sexual being belongs within discernable boundaries, one might perceive that gender and sexuality are stable, regardless of whether one's feelings transgress these boundaries.

However constrained by Xtube's prescriptive categories, it is by tagging that members have some opportunity to role-play within the 'scene of constraint.' As one might imagine, the tags reveal a highly developed and varied nomenclature and social organization. Yet, as I have already shown through Adler and Butler, this nomenclature is not purely particularistic and idiosyncratic. It is regulated by the social conventions of language and ideology. As such, members develop these folk taxonomies in fundamentally communal ways. Indeed, it is important to bear in mind that the purpose of these tags is to name and structure one's gender and sexual being within a broader social network. The practice of tagging one's homemade images and videos primarily occurs so that members enable others to access their representations, for the purpose of sexual arousal. In this way, members' perception, nomenclature, and identity of their own gender and sexuality are intimately tied to each other. That is, the 'power to tag' offers queer individuals a means for describing and structuring feelings of difference into coherent identities and particular social forms, and to relate those forms and identities to the way other people view them, to the way they view other people, and to the way other people view themselves, collapsing the distinction between exhibitionist and voyeur.

Participating within this social network also means that members of Xtube regulate each other's tags and, therefore, social organization. As we have seen, tagging patterns stabilize over time as the number of members increase. While this serves the strictly practical purpose of mostly effective image and video retrieval, it also functions to stabilize the nomenclature used by members to structure their own gender and sexuality in order to participate in Xtube's social relations. Members necessarily have to tag their images and videos in a way that allows for its retrieval by other members. To rely on purely idiosyncratic and particularistic nomenclature (i.e., either truly unique tags or complete mumbo jumbo) is to remove oneself from these social relations. Hence members structure their own gender and sexuality in a way that is accessible for others and allows for social engagement. In this way, a form of horizontal discipline occurs through the stabilization(s) of these categories. Social relations within Xtube require a common nomenclature that is regularized over time. This is not to say that nomenclature does not change over time, but that such a change occurs communally. Thus, however free one is to role-play within these categories, members necessary structure their feelings of difference and self-understanding into stable, coherent, and discernable social forms.

Overt intervention within queer subcultures especially seems to occur within fetishistic subcultures that are subsumed under a broader queer subculture, such as BDSM (Bondage, Discipline, Sadism, and Masochism). Websites serving the BDSM communities include collarme.com, bdsm.com, and recon.com, which claims to the "the world's largest hookup site for men into fetish gear" (n.d.). Within the subcultures that these sites serve, one's identity as dominant or submissive, top or bottom, master or slave is profoundly important to the social relations within that community. Members of these groups find sexual pleasure in the way these categories are explicitly stable, autonomous, hierarchical, antithetical, and even essential. These categories not only indicate social organization and self-understanding, members also sometimes express them as constitutive of one's destiny and 'true nature.' Because these categories so profoundly define the subculture and the people within it, members of this subculture have a high level of investment in debating the boundaries and meanings of these categories.

At times, intervening to create a common nomenclature runs up against disagreements about the exact meaning of a particular identity category. Most of the overt intervention into each other's self-understanding and nomenclature occurs within the discussion section of Xtube's wiki, but such intervention also occurs within the comments sections of images and videos. In one noteworthy instance of disagreement, when a member tagged his video "boi," several members debated the meaning of the term. Some members understood the term to mean, as Judith Halberstam 
(2006, 114) does, a "boyish gay man." Xtube's wiki page, which is edited by members, defines "boi" as any effeminate, submissive gay boy who wishes to distinguish himself from heterosexual boys, and who attempts to be alluring and seductive. ${ }^{18}$ Others insisted that the term refers to female-male transgender people. Still others felt it was any submissive man who preferred the receptive role in sex. Ultimately, in this case, members appear to agree to disagree about the meaning of the term "boi," which refuses to consolidate to a particular identity category. One might assume that this lack of consolidation leads to ineffectual retrieval, as a search for "boi" may result in an image that doesn't match what one had in mind. Yet, in agreeing to disagree, members seem to accept that the word has multiple meanings and retrieves a variety of results. My point here is not whether overt intervention always leads to single consolidation or whether tags, if consolidated, lead to effective retrieval. Overt intervention doesn't always lead to consolidation, and tags are never purely effective because language is not transparent. My point is only that these terms are deeply personal and social, such a part of one's identity in relation to others that one feels the need to intervene into others' self-understanding when confronted with difference. In doing so, a disagreement about the boundaries of the term leads to multiple consolidations of regulations and re-regulations that likely change over time. ${ }^{19}$

Tagging on Xtube draws our attention to a complex social and cultural structure of particular and various modes of sexual being and the relationship between those modes and particular configurations of sexual identity. Xtube's algorithm allows us to search keywords that not only retrieve images and videos tagged with that word, but also indicates, on the right-hand side of the screen, all of the tags related to that keyword. The algorithm calculates relativity based on how often different tags appear together when members' tag their images and videos. Xtube calls these tags "related tags." In a search for BDSM, the ten most related tags include slut, big, amateur, tits, wax, party, cock, candle, balls, and outdoor. In a search for bears (the name for a subculture within a broader gay subculture that usually consists of heavy-set men with hairy bodies), the ten most related tags are gay, daddy, daddies, hairy, mature, man, old, older, silver, and hirsute. For bareback (a term to describe sexual penetration between two men without the use of a condom), the ten most prominent related tags include cum, hardcore, anal, ebony, facial, muscle, black, jerkoff, chubby, and ass. In a search for domination, related tags include Asian, Thai, Japanese, worship, control, humiliation, black, pussy, BDSM, and transsexual.

While Xtube often lacks a controlled vocabulary for organizing queer subjects and desires, these tags reveal an abundance of language among members of Xtube's queer sexual subculture, which develop out of socio-citational relations. Each tag points to a number of tagging clusters that represents a particular fetishistic subculture, and tags can belong to a wide variety tagging clusters. These arrangements effectively represent an index or diagram of the social structure and network in which various representations of gender and sexuality occur. The relationship between some of these tags probably seems, if not natural, at least familiar: among many gay men, hairy is a characteristic of bear. Other tags, however, create unexpected associations and wondrous juxtapositions, such as the relation between the national identity Japanese and worship, without the adjectival modification common to a syntactical relationship, resulting in some ambiguity as to the precise way in which these words interact to represent a social relation. Furthermore, these tags, to some extent, allow for a corrective or supplement to Xtube's prescriptive categories. Whereas the prescriptive category transsexual is too narrow and too specific a term for describing other transgender ways of being, members often take it upon themselves to supplement that prescriptive category with tags such as transgender, transvestite, bisexual, crossdresser, femdom, dominatrix, woman, man, and queer-tags that seek to refine, counteract, or complicate Xtube's prescriptive category and articulate a different social form.

Many of these tags also reveal the way in which queer subcultures continue to reconstitute the nomenclature of the dominant culture, for better or worse. Consider, for example, the use of troublingly sexist words, such as slut, bitch, and pussy, as they appear in relation to other tags, such as humiliation, BDSM, and dominance. These words, often pejoratives for women within the dominant culture, seem particularly unexpected in describing representations of sex between men. Perhaps, like the words fag or queer, they function as a reclaiming of offensive terminology. More likely, however, these categories of sexual being reveal that a highly gendered dynamic of power relations exists within the sexual relations between men. As such, queer social organization and self-understanding are deeply embedded in that of the larger culture by reproducing social forms of gendered heterosexuality and sexism. 
As I have shown, tagging within Xtube reveals a highly developed and varied queer subculture that serves to structure social relations and self-understanding. These tags also indicate a form of horizontal discipline, either when members of Xtube overtly intervene into the self-understanding of other members, or when nomenclature necessary for effective retrieval and social engagement stabilizes over time as socialization occurs and social conventions develop. Finally, these social relations always occur within and against a dominant culture. We see this in the way queer subcultures sometimes reproduce social forms of gendered heterosexuality, but also in the way queer subcultural nomenclatures develop as a way to roleplay within the constraints of prescriptive boundaries of gender and sexuality.

\subsection{Conclusion}

Both Chauncey's analysis of a queer subculture during the World War I era and my analysis of a contemporary queer subculture online reveal the ways in which mechanisms of power around classifications of gender and sexuality are not always top-down or bottom-up. Instead, the weight of social discipline among members of sexual subcultures themselves helps to create these classifications, always in a complex relationship with the dominant culture. The complex cultural and social structures of members of these sexual subcultures reveal the particularity of various modes of sexual being and the relationship between those modes and particular configurations of sexual identity. Nevertheless, members of sexual subcultures do not name and organize their particular modes of sexual being in entirely idiosyncratic ways, free of culture and discipline. Instead, folksonomies develop within the conventions of a particular language and in relation to broader cultural ideology. Folksonomies offer an emancipatory potential against authoritative or prescribed notions of gender and sexuality, but such potential always occurs within a scene of constraint. While Foucault offers sophisticated understandings of the relationships between power, identity, language, and institutions, we must engage his work critically and understand its limitations. Doing so will help us to refine and complicate our own analyses of the role authority plays in our subject formation.

Further research should examine the specific development of various sexual nomenclatures within specific information institutions at various points in history. Such a project will help us continually refine our understandings of the relationship between power, au- thority, and identity. It will also enable us to develop concepts in relation to existing theories, rather than merely 'applying' or adapting concepts from other disciplines. The Newport and Xtube evidence indicates that we need to begin paying more attention to other social forms of sexual and gender nonconformity-other ways in which gender and sexual relations have been organized and understood, differentiated, named, and left deliberately unnamed. We need to specify the particularity of those modes of sexual being and the relationship between those modes and configurations of sexual identity as they develop within and against a dominant culture. Finally, and perhaps most importantly, we need to understand how organizing and structuring feelings of difference, as part of the 'power to name,' helps people resist social opprobrium and gives them strength to publically defy social convention. This paper provides a remarkable illustration of the extent to which gender and sexual boundaries are culturally constructed, and it reminds us that struggles over the demarcation of those boundaries are a central aspect in the study of gender and sexual knowledge organization.

\section{Notes}

1. I should immediately note that while Foucault arguably has had an outsize influence on discussions concerning the development of "homosexuality" as an identity category, there is no critical consensus on the historical circumstances that gave rise to the modern homosexual. Alan Bray (1982) has argued that the modern homosexual emerged at the close of the seventeenth century, with the emergence of an urban sexual subculture that sprang up around molly houses. George Chauncey (1985) has shown that medical discourse played little or no role in the shaping of working-class homosexual identities or categories by World War I, more than 30 years after the discourse had begun. John D’Emilio (1992) takes a Marxist approach and argues that what generates the conditions necessary for a homosexual identity is the historical development of capitalism, specifically its free-labor system. Meanwhile, Baudrillard (1988), who offers perhaps the most polemical challenge to Foucault, argues that desire has no place in History of Sexuality because desire and power are interchangeable.

2. This is not a criticism. Adler and Lau's research simply has a different focus than this essay. It 
would be unfair to expect their essays to speak, in detail, to every aspect of folksonomy.

3. A number of scholars have discussed the socially dynamic nature of tagging and its stabilizing effects. In addition to Golder and Huberman (2006), see also Halpin, Robu, and Shephard (2007).

4. This is not to say that purely idiosyncratic and particularistic tags don't exist. They do exist, sometimes in the form of complete nonsense or typos. Yet the point of this paper is to focus on folksonomic tagging, i.e., tagging that we create communally, either through a shared language or through social relations online, because the vast majority of tags within Xtube are folksonomic.

5. Ornelas $(2011,234)$ and Greenblatt $(1990,87)$ both rightly point out that gays and lesbians have long thought the term "homosexual" too clinical. But it is worth noting that its early use served as a rhetorical tool to further the rights of "homosexuals" during the European fin-de-siècle.

6. Havelock Ellis famously pointed out, "Homosexuality' is a barbarously hybrid word . .." (1897, 1) - being an incongruity of both Greek (bomo) and Latin (sexualis).

7. As Chauncey notes, see also the role of psychiatrists in the records of courts-martial conducted from 1941-1943 held at the National Archives (Army A. G. 250.1) and the 1944 investigation of lesbianism at the Third WAC Training Center, Fort Oglethorpe, Georgia (National Archives, Modern Military Filed Branch, Suitland Maryland, R. G. 159, Entry 26F). See also Bérubé, Allan. 2000. Coming out under fire. New York: Simon \& Schuster.

8. Clinton's Executive Order prohibits employment discrimination based on sexual orientation within the Federal Government. See the Federal Register, Vol. 63, No. 105, Tuesday, June 2, 1998. Noteworthy, the U.S. government still allows government contractors to discriminate against people based on sexual orientation.

9. Lakoff (1997) has suggested a similar phenomenon in his examination of linguistics, cognitive science, and categories.

10. For more detail about Halperin's course, see Bloomer (2007), Uman (2011), and Halperin (2012).

11. Noteworthy, 'fairy' did not refer to a mythical being from folklore, but, in fact, developed as a portmantean of 'French artist'-a word that de- scribed men who dressed in women's clothes (Chauncey 1985, 193).

12. Kinsey's Sexual Behavior in the Human Male (1948) sold more than 200,000 copies when it was published, and it stayed on the New York Times best-seller list for many months, making it the most popular science book ever published at that time. His Sexual Behavior in the Human Female (1953) would eventually outsell its predecessor. Kinsey also participated in a large publicity junket that included interviews in popular media, including magazines, newspapers, and radio. Retrieved April 14, 2012 from http://www. kinseyinstitute.org/services/2003/media-reaction. html

13. Mind you, this is now roughly $50-60$ years after Foucault claims that the proliferation of medical and legal discourse caused people to identify as homosexual. One of the things Foucault misses that Chauncey shows is just how differently same-sex sexual perversion was popularly understood within that period.

14. See especially Puar (2007).

15. The quote comes from Xtube's wiki, http:// wiki.xtube.com/index.php? title $=X$ Tube\&action $=$ purge. The figure for the number of 'members' comes from Xtube's hompage, http://www.xtube. com/. Both retrieved April 17, 2012.

16. I elaborate further on this point in my essay "Tabulating Queer" (Keilty 2009, 246).

17. The relation between a dominant culture and Xtube's administrators may confuse some readers. By way of clarification, let me explain that the prescriptive categories of Xtube's administrators certainly participate in a dominant Western culture, but always in a complicated way. At times, Xtube's prescriptive categories reflect the dominant heteronormative organizations and narratives of sex, sexual relations, and desire recognizable to a U.S. or Canadian audience. At other times, Xtube's categories name fetishes or subcultural sexual communities that a dominant culture finds taboo. As a result, some readers may question where power is being exercised. In this essay, I mostly focus on vertical power that stems from a dominant culture, but vertical power also comes from Xtube's administrators, which I discussed in a previous essay (Keilty 2009). Vertical power, as I have said, occurs simultaneously with horizontal power, which occurs between members of a subculture. I hope I have avoided any 
slippage between Xtube and a dominant culture in this essay.

18. Retrieved April 21, 2012 from http://wiki.xtube. com/index.php? title $=$ Boi\&action $=$ purge

19. I am aware that "super tagging" or "tag bombing" is another common form of overt intervention within online tagging. I didn't see much of it on Xtube, so it doesn't make its way into this essay. Future research might examine how "super tagging" or "tag bombing" functions as a form of social discipline and regulation.

\section{References}

Adler, Melissa. 2009. Transcending library catalogs: a comparative study of controlled terms in Library of Congress Subject Headings and user-generated tags in LibraryThing for transgender books. Journal of web librarianship 3: 309-31.

Adler, Melissa. 2012. For sexual perversion see paraphilias: disciplining sexual deviance at the $\mathrm{Li}$ brary of Congress. PhD diss., University of Wisconsin-Madison.

Adler, Melissa. 2013 forthcoming. Paraphilias: The perversion of meaning in the Library of Congress catalog. In Keilty, Patrick, and Dean, Rebecca eds., Feminist and queer information studies reader. Los Angeles: Litwin Books.

Armstrong, Nancy. 1990. Desire and domestic fiction: a political history of the novel. Oxford: Oxford University Press.

Baudrillard, Jean. 1988. Forget Foucault. Los Angeles : Semiotext (e).

Bauer, Heike. 2009. English literary sexology: translations of inversion, 1860-1930. New York: Palgrave.

Berman, Sanford. 1981. The joy of cataloging. Phoenix, Ariz.: Oryx Press.

Berman, Sanford. 1990. Foreword. In Gough, Cal, and Greenblatt, Ellen eds., Gay and lesbian library service. Jefferson, NC: McFarland \& Company, pp. $\mathrm{xv}-\mathrm{xx}$.

Bérubé, Allan. 2000. Coming out under fire: the history of gay men and women in World War Two. New York: Simon \& Schuster.

Bloomer, Jeffrey. 2007. "How David Halperin taught me to be gay (sort of)." The Michigan Daily, February 14. Available http://www.michigandaily.com/ content/how-david-halperin-taught-me-be-gaysort.

Bowker, Geoffrey C., and Star, Susan Leigh. 1999. Sorting things out: classification and its consequences. Cambridge, Mass.: MIT Press.
Bray, Alan. 1988. Homosexuality in renaissance England. London: Gay Men's Press.

Bristow, Joseph. 1997. Sexuality. New York: Routledge.

Butler, Judith. 2004. Undoing gender. New York: Routledge.

Campbell, D. Grant. 2001. Queer theory and the creation of contextualized subject access tools for gay and lesbian communities. Knowledge organization 27: 122-31.

Campbell, D. Grant. 2004. A queer eye for the faceted guy: how a universal classification principle can be applied to a distinct subculture. In McIlwaine, Ia C. ed., Knowledge organization and the global information society: proceedings of the $8^{\text {th }}$ international conference of the International Society for Knowledge Organization (London, England, July 13-16). Advances in knowledge organization, no. 9. Würzburg: Ergon, pp. 109-13.

Chauncey, George. 1983. "From sexual inversion to homosexuality": medicine and the changing conceptualization of female deviance. Salmagundi 58/59: 114-46.

Chauncey, George. 1985. Christian brotherhood or sexual perversion? Homosexual identities and the construction of sexual boundaries in the World War One era. Journal of social history 19: 189-212

Chauncey, George. 1995. Gay New York: gender, urban culture, and the making of the gay world, $1890-$ 1940. New York: Basic Books.

Christiansen, Ben. 2008. Minoritization vs. universalization: lesbianism and male homosexuality in LCSH and LCC. Knowledge organization 35: 229-38.

Christiansen, Ben. 2011. Interfiling intersex: how Dewey classifies intersex in theory and practice. In Greenblatt, Ellen ed., Serving LGBTIQ library and archive users: essays on outreach, service, collections and access. Jefferson, NC: McFarland \& Company, 201-11.

D’Emilio, John. 1992. Making trouble: essays on gay bistory, politics and the university. New York: Routledge.

Dollimore, Jonathan. 1991. Sexual dissidence: Angustine to Wilde, Frend to Foucault. Oxford: Clarendon Press.

Ellis, Havelock. 1897. Studies in the psychology of sex, volume 1. London: University Press.

Faderman, Lillian. 2002. Surpassing the love of men: romantic friendship and love between women from the Renaissance to the present. New York: Harper Collins.

Foucault, Michel. 1977. The order of things: an archeology of the human sciences. New York: Pantheon. 
Foucault, Michel. 1978. The history of sexuality: vol. 1, an introduction. Translated by Robert Hurley. New York: Random House.

Foucault, Michel. 1972. The archaeology of knowledge and the discourse on language. Translated by A. M. Sheridan Smith. New York: Pantheon.

Golder, Scott A., and Huberman, Bernardo A. 2006. Usage patterns of collaborative tagging systems. Journal of information science 32: 198-208.

Greenblatt, Ellen. 1990. Homosexuality: the evolution of a concept in the Library of Congress Subject Headings. In Gough, Cal, and Greenblatt, Ellen eds., Gay and lesbian library service. McFarland, NC: McFarland \& Company, 75-101.

Greenblatt, Ellen. 2011. The treatment of LGBTIQ concepts in the Library of Congress subject headings. In Greenblatt, Ellen ed., Serving LGBTIQ library and archive users: essays on outreach, service, collections, and access. Jefferson, NC: McFarland \& Company, 212-28.

Halberstam, Judith. 2006. Boys will be... bois?: or, transgender feminism and forgetful fish. In Richardson, Diane, McLaughlin, Janice, and Casey, Mark E. eds., Intersections between feminist and queer theory. New York: Palgrave Macmillan, 97-115.

Halperin, David. 1995. Saint Foucault: towards a gay hagiography. Oxford: Oxford University Press.

Halperin, David. 2012. How to be gay. Cambridge, Mass.: Harvard University Press.

Halpin, Harry, Robu, Valentin, and Shephard, Hana. 2007. The complex dynamics of collaborative tagging. In Williamson, Carey, and Zurko, Mary Ellen eds., WWW 2007: proceedings of the $16^{\text {th }}$ international World Wide Web conference, May 8-12, 2007, Banff, Alberta, Canada, 211-20. Available http:// www2007.org/proceedings.html.

Johnson, Matt. 2010. Transgender subject access: history and current practice. Cataloging $E$ classification quarterly 48: 661-83.

Keilty, Patrick. 2009. Tabulating queer: space, perversion, and belonging. Knowledge organization 36: 240-48

Kinsey, Alfred C., Pomeroy, Wardell Baxter, and Martin, Clyde E. 1948. Sexual behavior in the buman male. Philadelphia: W. B. Saunders Co.

Kinsey, Alfred C., Pomeroy, Wardell Baxter, and Martin, Clyde E. 1953. Sexual behavior in the buman female. Philadelphia: W. B. Saunders Co.

Kipnis, Laura. 1999. Bound and gagged: pornography and the politics of fantasy in America. Durham, NC: Duke University Press.
Lakoff, George. 1997. Women, fire, and dangerous things: what categories reveal about the mind. Chicago: Univ. of Chicago Pr.

Lau, Andrew. 2008. Burning down the shelf: standardized classification, folksonomies, and ontological politics. InterActions: UCLA journal of education and information studies 4n1: article 4. Available http://escholarship.org/uc/item/74p477pz\#.

Miller, D. A. 1989. The novel and the police. Berkeley: University of California Press.

Mudimbe, Valentin Y. 1988. The invention of Africa: gnosis, philosophy, and the order of knowledge. Bloomington: Indiana University Press.

Olson, Hope. 1998. Mapping beyond Dewey's boundaries. Constructing classificatory space for marginalized knowledge domains. Library trends 47: 233-54.

Olson, Hope A. 2001. The power to name: representation in library catalogs. Signs: journal of women in culture and society 26: 639-68.

Olson, Hope A. 2002. The power to name: locating the limits of subject representation in libraries. Boston: Kluwer.

Olson, Hope. 2007. How we construct subjects: a feminist analysis. Library trends 56: 509-41.

Ornelas, Analisa. 2011. Queer as folksonomies. In Greenblatt, Ellen ed., Serving LGBTIQ library and archive users: essays on outreach, service, collections, and access. Jefferson, NC: McFarland \& Company, 229-39.

Puar, Jasbir K. 2007. Terrorist assemblages: homonationalism in queer times. Durham, NC: Duke University Press.

Rawson, J. K. 2009. Accessing transgender // desiring queer(er?) archival logics. Archivaria 68: 123-40.

Recon. n.d. Recon-photo profiles for gay men. Retrieved April 20, 2012 from http://www.recon. $\mathrm{com} /$.

Sedgwick, Eve Kosofsky. 1990. Epistemology of the closet. Berkeley: University of California Press.

Ulrichs, Karl Heinrich. 1994. The riddle of "manmanly" love: the pioneering work on male homosexuality, 2 vols. Translated by Michael A. Lombardi-Nash. New York: Prometheus Books.

Uman, Selen. 2011. Halperin teaches "how to be gay." Yale Daily Nerws. October 6, 2011. Available http:// www.yaledailynews.com/news/2011/oct/06/ halperin-teaches-how-to-be-gay/.

Weeks, Jeffrey. 1977. Coming out: Homosexual politics in Britain from the nineteenth century to the present. London: Quartet Books.

Xtube. n.d. Xtube: free porn. Retrieved April 17, 2012 from http://www.xtube.com/. 